\title{
Moral and ethical realism and unbounded organization
}

Howard Richards, in his recently published article in the Journal of Critical Realism Moral (and Ethical) Realism, offers practical ethics for our times, embedded in finding of the natural sciences. A companion volume written Wh Dr Gavin Andersson in Community is a step step guide to realist practice. In other works he develops the fateful consequences of two 'Staggering Facts.' One is the dependence of production on accumulation (profit); the other is the chronic weakness of effective demand especially in his forthcoming Community Development.

Dofessor Richards' work is perhaps best introduced by his Oxford of his book The Dilemmas of Social Democracies: "The key insight, whic reflects movements in the human sciences generally, is to foreground the role of culture in the reproduction of the obstacles to the realisation of just world. Diagnosis is the first step moral or social. In this book, we have thrilling beginning." The book consists of case studies of social democracy in Spain, Sweden, Austria, South Africa, and Indonesia and a critical history of World Bank policies. Its thesis is that the constitutive rules of capitalism make socia democracy an unsustainable project. A deeper analysis of cultural change and how to facilitate it is needed to make
social democracy possible and indeed to make the survival of humanity and the biosphere possible. Richards and co-author Joanna Swanger offer such deeper analysis.
Richards suggestst that realism works with, not
against, existing religion, existing hits against, existing religion, existing humanist
non-religious ethics, and with whatever is giving
meaning and functionality to life.

depends upon the expectation of producers and investors to make a profit on this production, which depends on the expectation of a sufficient number of sales. These two facts together reflect the basic social structure that evolved historically in the successor states of the Roman Empire and was later imposed the global economy. A consequence of the Staggering Facts will be sufficient sales to make the profit which justifies the investment required to begin production in the first place. This is what is meant by a chronic shortfall of effective demand. These are not empirica facts discovered by positivist economists; they are consequences of the constitutive rules of the system, i.e. of social structures that are products of history and do not exist at all in African traditions. Cultura structures are ethical structures, i.e. norms. Thus ethics, constituted by history is fundamental for causal explanation in social science, for social teconstruction

The demand is also ineffective and falling chronically short because it ployment. This two Staggering Facts will leave many without access to work. Professor Richard argues that such consequences have led to the structural humiliation of many people. A forthcoming work, Economic Theory and Community Development (ETCD) with Gavin Andersson applies this theoretical focus to the growing problem of mass unemployment. ETCD compares more and less successful attempts to solve this problem in India, South Afric and Sweden.

The authors forward the conclusion that unbounded organization (UO) building local self-reliance is crucial. Grassroots

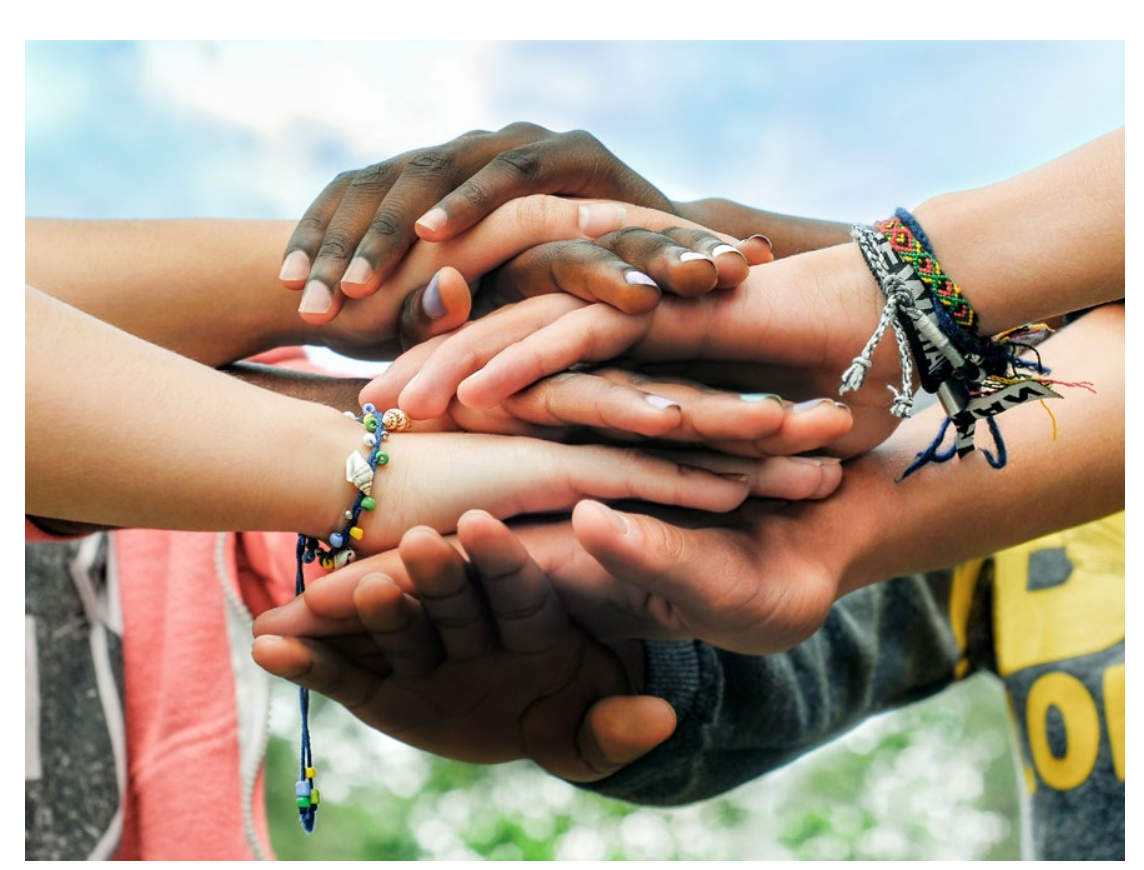

community development methods, such as the Asset Based Community Obama practiced after taking his first degree) and the Organization Workshop approach developed in Latin America and Africa are therefore also crucial. The book Unbounded Organizing in Community by Andersson and Richards is a practical step by step guide to how to

\section{MORAL AND ETHICAL}

\section{REALISM EXPLAINED}

Professor Richards takes a moral

realist approach to social issues. Moral

if it is expressed in the terms in which dignity is understood in the person's others, but with a few exceptions all. cultures work better than normlessness.

There are three core components to Professor Richards' moral realism. Firstly, he claims that the way people should act, and by extension, the way communities should be organised, ought to lead to people acting to meet human needs in harmony with nature. Secondly, nature judges culture; for example, the climate crisis makes green living a moral imperative. Thirdly, Professor Richards

Richards argues for celebrating diversity while simultaneously unifying all human behaviour under an ethic of respect for universal human rights.

and ethical realism argues that ethical statements refer to objective claims about the world. It has a sordid past to live down, since in the past other versio calling themselves realism have been used to justify homophobia, patriarchy and savage capitalism. In Richards' version, part of its realism is working with existing moral codes. Realism works with, not against, existing religion, existing humanist non-religious ethics, and wh whatever is giving meaning and frespect. Respect can only mean dignity favours respecting people's existing moral practices and beliefs, including the practices and beliefs of liberals, unless tor making an exception. This final point celebrates moral diversity. Richards argues for uniffing diversity while simultaneously unitying all human behaviour under an

DR ANDERSSON'S CONCEPT OF UNBOUNDED ORGANIZATION The concept of unbounded organization was first laid out by Dr Andersson. 


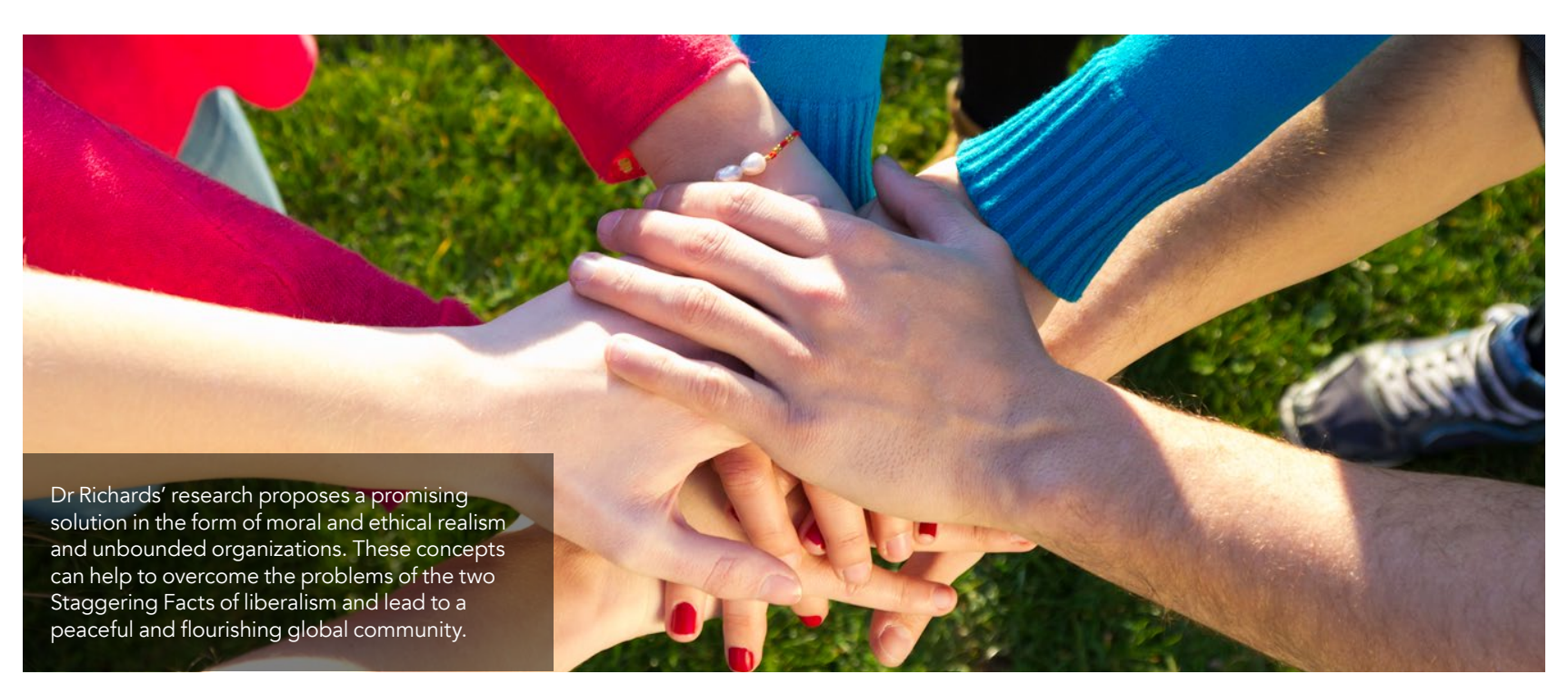

In order to define it, it is useful to distinguish it from bounded organization, Which is auto-centric, while $U \mathrm{O}$ is not. upon them set of rules. This is the dominant organizational structure of society today. Society is conceived as a set of independent organizations each in its own silo seeking to maximise its profts and/or to meet its own objectives whatever they may be.

UOs align across sectors for the common good. By working together toward society's objectives, like ending poverty and crime and reversing globa warming, they are better able to meet the natural needs of humanity. This is not totalitarianism or an all-powerful
government. It is advocating a philosophy government. It is advocating a philoso
of ethical cooperation among the public sector the private neighbourhood community orgaizations and all the myriad organizations of society Richards suggests as an example the construction of millions of units of housin for the homeless and the shack-dwellers in South Africa. Neighbours worked with neighbours to carry out self-help auto-construction organized by a People's Housing Movement. Government agencies, banks, building companies,
foreign aid donors and others all aligned to the same goal.

Organizations become unbounde when they open themselves up to collaboration with other organizations in different communites and sectors of the economy, and when they 'think outside
the box' realising that for any given problem the number of ways to solve it is in principle unlimited. UO intersects Wh the moral and ethical realism of of determining the right way to act. open to social innovations and choosing

to be responsible stewards of resources.

\section{UNDERSTANDING}

THE GLOBAL ECONOMY

Much of Professor Richards' work is

dedicated to explaining and improving the social sciences. For example, his book

sething, which has resulted, for example, wh much of eastern Spain being Every neighbourhood should be ables. to meet basic needs whatever happens in the global economy. the Peace Education Centre at Columbia University in New York (now retired) is a gold standard researcher in the field of peace studies. She writes that Dr Richards' work is "an especially instructive model Understanding the Global Economy is

of modes of scholarship, argument

\section{Dr Richards' research proposes a} organizations.

an analysis of how economists attempt Richards is keen to note the practical failure as well as the logical incoherence of neoliberalism. ETCD advocates. governable economic growth (properly measured, not measured by GDP) that keeps planet Earth within its own means. UOs, working on a global scale, can be ecological, while promoting higher quality of life for all residents of dependence of people for their daily bread on the confidence of global investors. As in nature, social system should be redundant and plural. The penchant of economists for finding and exposition that, I believe, should be constitutive to the practice of peace bilits "She also notes Dr Richards' to determine and put into practice ethical norms. This approach is a practical way the needs of humanity, creating peaceful and just societies.

The global economy is failing to fulfil the needs of all humanity. Dr Richards' research proposes a promising solution in the form of moral and ethical realism and unbounded organizations. These concepts can help to overcome the problems of the two Staggering Facts and flourishing global community. ability to use empirical scientific research
Betty Reardon, founder and director of promising solution in the form of moral and ethical realism and unbounded phenomena they study and in this planet. A key is to end the physical

\section{Behind the Research}

\section{Professor Howard Richards}

E: howardrichards8@gmail.com E: howard.richards@usach.cl
W: www.chileufu.cl W: www.unboundedorganization.org

\section{Research Objectives}

Professor Howard Richards is a philosopher of Social Science, who works with the concepts of basic cultural structures and constitutive rules.

\section{Detail}

049 Andres Bello, Limache Chile 114 Gay Drive Ventura CA 93003 USA

Bio

Howard Richards holds the title of Research Professor of Philosophy at Earlham College USA. He studied philosophy with Richard Rorty at Yale with Rom Harré at Oxford. He teaches philosophy of science at the University of Santiago Chile and ethics in the EMBA at the University of Cape Town.

Collaborators Gavin Andersson - Evelin Lindner - Joanna Swanger - Catherine Hoppers Earlham

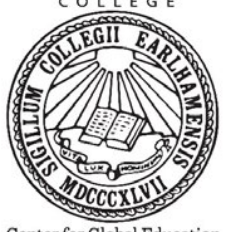

\section{References} Andersson, G. and Richards H. (2012). Bounded and
Unbounded Organization, AFRICANUS, [online]. 42(1), pp. 98-119. Available at: $h$ http://unboundedorganization.org/ wp-content/up

Andersson, G. and Richards, H. (2015). Unbounded Organizing in Community. Dignity Press. Richards, H. (2019). Moral (and Ethical) Realism. Journal of

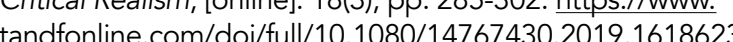

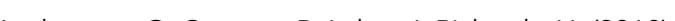
Andersson, G. Carmen, R. Labra, I. Richards, H. (2018)
Organization Workshop. Beyond the Workplace: Groups, Activity and the Shared Object. Mind, Culture, and Activity, 25:1, 86-99, DOI: 10.1080/10749039.2017.1386218. Richards, H. (2018). Understanding Economy, [online]. http:// www.understandingeconomy.org/.

Andersson, G. 2019 Unbounded Organization. wmm. unboundedacademy.org. Richards, H. 2018. On the intransitive objects of the social
(or human) sciences, Journal of Critical Realism, Volume 17, pp. 1-16.

Howard Richards, Moral (and ethical) Realism. Journal of Critical Realism. Volume 18 (2019) pages 285-302. Howard Richards, Following Foucault: The Trail of the Fox. Stellenbosch: Sun Media, 2018.

Howard Richards, The Evaluation of Cultural Action. London Macmillan, 1985 Howard Richards and Joanna Swanger, The Dilemmas of
Social Demcracies. Lanham: Rowman and Littlefield, 2006.

\section{Personal Response}

\section{Where next for the global economy? What are} the practical steps for moving towards unbounded organization?

1: Social/emotional/moral education and/or therapy leading to mental health and a pro-social attitude. . Intellectual education starting with problems that understanding of their causes and an appetite for lifelong learning

Identifying and supporting growth points where digning across sectors for the common good is making the structural changes needed to build plural with nature. 